\title{
Galactorrhoea, hyperprolactinaemia, and pituitary adenoma presenting during metoclopramide therapy
}

\author{
B. T. COOPER* \\ M.D., M.R.C.P. \\ R. A. MOUNTFORD* \\ M.D., M.R.C.P. \\ C. MCKeE† \\ B.Pharm, M.P.S. \\ *Department of Medicine, University of Bristol and $†$ Regional Drug Information Centre \\ Bristol Royal Infirmary, Bristol BS2 $8 \mathrm{HW}$
}

\begin{abstract}
Summary
A 49-year-old woman presented with a one month history of headaches, loss of libido and galactorrhoea. She had been taking metoclopramide for the previous 3 months for reflux oesophagitis. She was found to have substantially elevated serum prolactin levels and a pituitary adenoma, which have not been previously described in a patient taking metoclopramide. The drug was stopped and the serum prolactin level fell progressively to normal with resolution of symptoms over 4 months. This suggested that contrary to our original impression that she had a prolactin-secreting pituitary adenoma which had been stimulated by metoclopramide, she had metoclopramide-induced hyperprolactinaemia and an incidental pituitary tumour.
\end{abstract}

\section{Introduction}

Metoclopramide is a potent stimulator of prolactin release (NcNeilly et al., 1974) as it blocks dopamine receptors (Yeo et al., 1979). As would be expected, galactorrhoea has been described in patients taking metoclopramide (Robinson, 1973). However, no patient has yet been described who, after presenting with galactorrhoea while taking metoclopramide, was found to have a radiologically obvious pituitary tumour. We describe such a case, but contrary to our initial impression, the hyperprolactinaemia appeared to be related to the drug therapy and the tumour seemed to be an incidental finding.

\section{Case history}

A 49-year-old married woman, presented in February 1979 to the gastrointestinal clinic with a 2-year history of retrosternal and epigastric pain with weight loss. In 1967, she underwent partial gastrectomy with a Roux-en-y gastrojejunal anastomosis for duodenal ulceration. She had had one pregnancy 24 years previously and in 1960 she underwent hysterectomy for dysfunctional uterine bleeding. There were no abnormal features on examination. In May 1979, she was admitted for investigation but the only abnormality found was reflux oesophagitis. She was treated with cimetidine $\subseteq$ and antacid (Gaviscon) over the subsequent $10 \rightarrow$ months with little benefit. In April 1980, cimetidine was stopped and she was prescribed metoclopramide (Maxolon) $10 \mathrm{mg}$ three times daily in $\vec{\emptyset}$ addition to Gaviscon. At follow up in July 1980 요 she complained of galactorrhoea, loss of libido and headache for a month. Her optic fundi and visual fields were normal. Her plasma electrolytes and serum cortisol, growth hormone, thyroxine and free thyroxine index were normal but her $\Phi$ serum prolactin was $3239 \mathrm{mu} . / 1$ (normal 40-360 mu./1). Serum FSH was at a normal postmenopausal level ( $>25$ i.u./l) but LH was lower at $8 \cdot 3$ i.u./l. A skull X-ray (Fig.) showed a double floor to the sella with erosion of the lamina dura posteriorly consistent with a pituitary adenoma. A CT scan 3 showed no suprasellar extension. A prolactinoma was suspected, perhaps provoked or unmasked by 3 . metoclopramide. Metoclopramide was stopped and $\delta$ over the next 4 months her serum prolactin levels 3 progressively fell to normal levels and her symptoms 응 resolved. In view of the improvement in her symptoms, the fall in serum prolactin levels, and the absence of suprasellar extension, there seemed no indication for surgery and she is being followed up. $\sigma$

\section{Discussion}

It seems unlikely that any other drug caused the patient's symptoms. Cimetidine had been stopped 2 months before the onset of symptoms. The patient is the first to be described who was found to have $\stackrel{\circ}{\rightarrow}$ hyperprolactinaemia and a pituitary adenoma while taking metoclopramide. It is just possible that this patient developed a pituitary adenoma on $\vec{\Phi}$ 


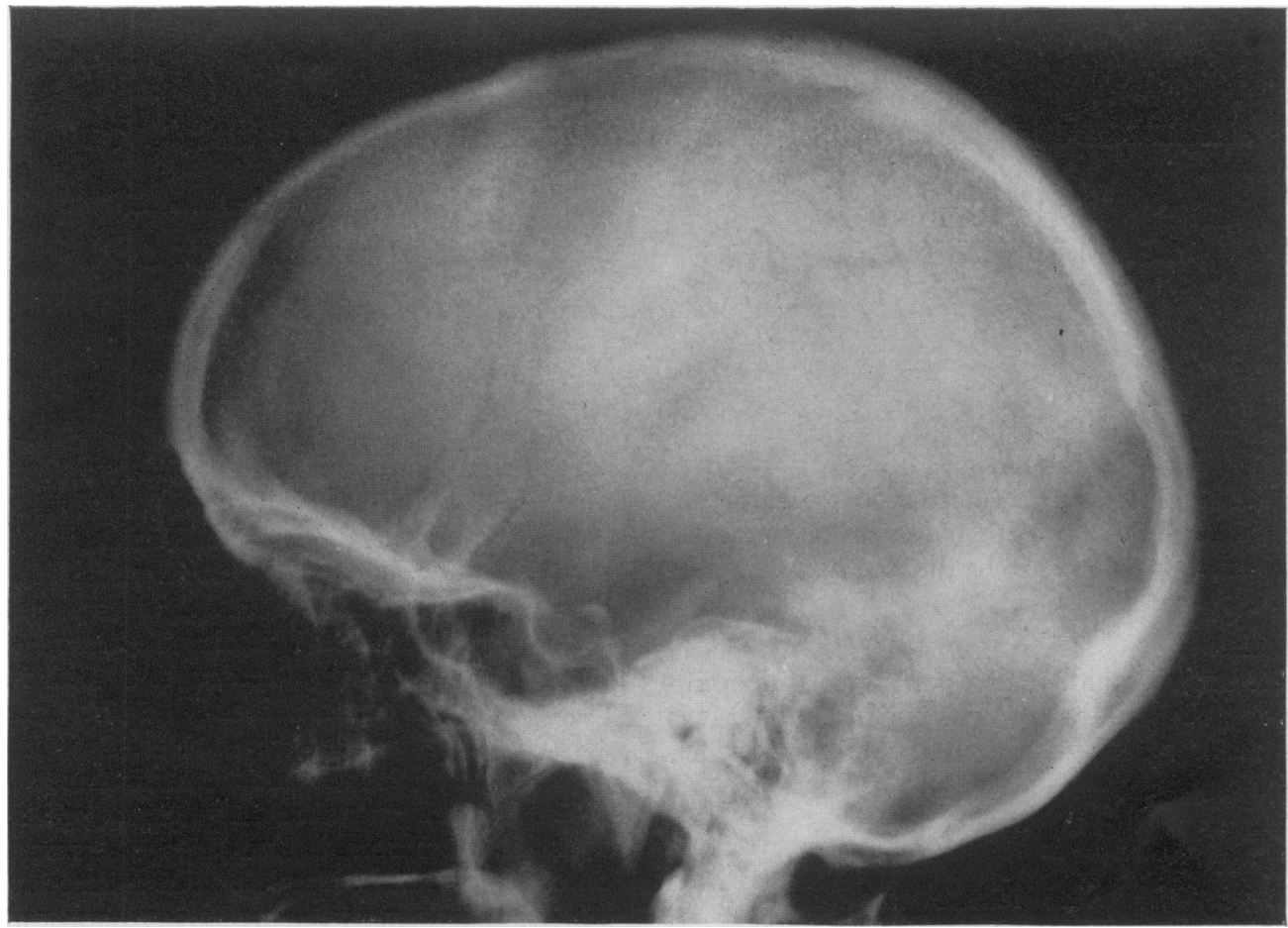

FIG. 1. Lateral view of skull showing a double floor of the sella with erosion of the lamina dura posteriorly.

metoclopramide or that metoclopramide unmasked a silent prolactinoma. Oestrogens, which also raise prolactin levels, have been blamed for causing pituitary tumours (Sherman et al., 1978). However, it is more likely that our patient had an asymptomatic pituitary tumour, which can occur in $5-10 \%$ of individuals (Sherman et al., 1978), and coincidentally had metoclopramide-induced hyperprolactinaemia. This interpretation is strongly suggested by the steady fall in prolactin levels after stopping metoclopramide. This suggests that metoclopramide induced the hyperprolactinaemia and this does not occur in true prolactinomas (Cowden et al., 1979).

While the patient's galactorrhoea was caused by her hyperprolactinaemia, the cause of her headache and loss of libido was not so obvious. However, it seems possible that her headache was related to expansion of normal pituitary tissue under the stimulus of metoclopramide in a pituitary already containing an adenoma. Her loss of libido might have been related to hyperprolactinaemia itself although this symptom is not prominent in hyperprolactinaemic women; it is however very common in hyperprolactinaemic men (Thorner, 1977).

The development of a symptomatic prolactinoma must be a theoretical risk for patients taking metoclopramide but contrary to our original impression, this does not appear to have happened here. It would have been easy to fall into the trap of assuming that the tumour was provoked by metoclopramide therapy because metoclopramide stimulates prolactin release and because pituitary adenomas can secrete prolactin. As the diagnosis of prolactinoma would have been erroneous and could have had therapeutic implications, our case provides a cautionary tale.

\section{References}

Cowden, E.A., Ratcliffe, J.G., Thomson, J.A., McPherSon, P., Doyle, D. \& Teasdale, G.M. (1979) Tests of prolactin secretion in diagnosis of prolactinomas. Lancet, i, 1155.

MCNeilly, A.S., Thorner, M.O., Volans, G. \& Besser, G.M. (1974) Metoclopramide and prolactin. British Medical Journal, 2, 729.

RobINSON, O.P.W. (1973) Metoclopramide; side effects and safety. Postgraduate Medical Journal, 49 (suppl. 4), 77.

Sherman, B.M., Harris, C.E., Schlechte, J., Duello, T.M., Halmi, N.S., VAN GILDER, I., Chapter, F.K. \& Grassner, D.K. (1978) Pathogenesis of prolactin secreting adenomas. Lancet, ii, 1019.

ThORNer, M.O. (1977) Prolactin. Clinics in Endocrinology, 6, 201.

Yeo, T., Thorner, M.O., Jones, A., Lowry, P.J. \& Besser, G.M. (1979) The effects of dopamine, bromocriptine, lergotrile and metoclopramide on prolactin release from continually perfused columns of isolated rat pituitary cells. Clinical Endocrinology, 10, 123. 